\title{
Hypoglossal Nerve Stimulation for Obstructive Sleep Apnea: A Novel Surgical Approach (A Review of Literature)
}

\author{
1 Jaseetha Sasidharan, ${ }^{2}$ Aditya Bhargava, ${ }^{3}$ Harsh Vardhan, ${ }^{4}$ Amit Gupta
}

\begin{abstract}
Introduction: Obstructive sleep apnea (OSA) is associated with considerable health risks. Continuous positive airway pressure (CPAP) is the gold standard treatment, but its efficacy is reduced by inadequate adherence to treatment. Surgical treatment for OSA has evolved to neuromodulation with the advent of hypoglossal nerve stimulation.
\end{abstract}

Objectives: To evaluate the efficacy of hypoglossal nerve stimulation in the treatment of OSA syndrome.

Methods: Studies were included that evaluated the efficacy of hypoglossal nerve stimulation to treat OSA. Six prospective studies were included in this trial.

Results: Six studies with a total of 242 patients were included in this review. All the studies demonstrated a reduction in apnoea hypopnoea index $(\mathrm{AHI})$, Oxygen desaturation index (ODI), and Epworth sleepiness scale (ESS). Despite using different hypoglossal nerve stimulators in each subgroup analysis, no significant difference was found in any of the comparisons, suggesting equivalent efficacy regardless of the system in use.

Conclusion: Hypoglossal nerve stimulation (HGNS) therapy has so far proved to be an effective alternative treatment of obstructive sleep apnea in CPAP intolerant selected group of patients.

Keywords: Continuous positive airway pressure, Hypoglossal nerve stimulation, Obstructive sleep apnea.

How to cite this article: Sasidharan J, Bhargava A, Vardhan $\mathrm{H}$, Gupta A. Hypoglossal Nerve Stimulation for Obstructive Sleep Apnea: A Novel Surgical Approach (A Review of Literature). Indian Sleep Med 2018;13(4):67-70.

Source of support: Nil

Conflict of interest: None

\section{INTRODUCTION}

Obstructive sleep apnea (OSA) is characterized by repetitive upper airway collapse during sleep, causing hypoxemia and sleep fragmentation that leads to daytime sleepiness and increased risk of cardiovascular incidents, motor vehicle, and occupational accidents. ${ }^{1-3}$

\footnotetext{
${ }^{1}$ Assistant Professor, ${ }^{2}$ Professor, ${ }^{3,4}$ Senior Resident

${ }^{1-4}$ Department of Ear, Nose and Throat, Employees State Insurance Post Graduate Institute of Medical Sciences and Research, Basaidarapur, New Delhi, India

Corresponding Author: Amit Gupta, Senior Resident, Department of Ear, Nose and Throat, Employees State Insurance Post Graduate Institute of Medical Sciences and Research, Basaidarapur, New Delhi, India, Phone: +918054099433, e-mail: dramit70@gmail.com
}

The prevalence of sleep apnea in north India is $13.7 \%{ }^{4}$ The gold standard for the treatment of OSA is CPAP. ${ }^{5}$ It has been demonstrated that successful CPAP treatment improves systemic hypertension and prolongs survival. ${ }^{6}$ However, the clinical effectiveness of CPAP is often limited by low patient acceptance, poor tolerance, and suboptimal compliance. ${ }^{7}$ Therefore, non-CPAP alternatives for the treatment of sleep disordered breathing, such as oral appliance therapy with custom-made, titratable mandibular advancement devices, surgery, or upper airway stimulation (UAS) have gained growing interest. ${ }^{8-11}$ UAS therapy, which uses electrical stimulation of the hypoglossal nerve, has been reported to be safe and efficacious in a select group of OSA patients who cannot or will not use CPAP as primary treatment. ${ }^{12,13}$ In 1978, Remmers et al. were the first to report the direct relationship between loss of genioglossus muscle activation during sleep and upper airway closure in patients with OSA. ${ }^{14}$ This finding led to early attempts to treat the disorder by electrical stimulation of the pharyngeal muscles with transcutaneous, intraoral and intramuscular electrodes. ${ }^{14-16}$ Several subsequent projects since then have attempted to prove the usefulness of hypoglossal nerve stimulation (HGNS) as a novel therapeutic approach to sleep apnea. ${ }^{17}$

\section{Concepts of Hypoglossal Nerve Stimulation Devices}

The clinical model of HGNS was first attempted atthe Johns Hopkins University, and the study was completed in 2001. ${ }^{18}$ Following the published technical limitations of this study, improvements took place; in 2011 three clinical trials were sponsored by different firms:

- Apnex (St. Paul, MN, USA)

- Inspire (Maple Grove, MN, USA)

- ImThera Medical (San Diego, CA, USA)

Inspire, and Apnex trials are based on unilateral stimulation of medial branch of the hypoglossal nerve with inspiration while in ImThera trial, the stimulus was given to the main trunk of the nerve and delivered at both inspiration and expiration, thereby excluding the need of an inspiratory sensor. ${ }^{13}$

The food and drug administration (FDA) approved device is Inspire-II. The star trail with large multicenter one-year phase 2 to 3 trial was completed in 2014. A total of 126 patients with inclusion criteria consisting of CPAP nonadherence, body mass index $(\mathrm{BMI})<32 \mathrm{~kg} / \mathrm{m}^{2}$, AHI 
between 20 to 50 events/hour, the absence of complete concentric collapse (CCC) on drug-induced sleep endoscopy (DISE) at velum, central apnea were enrolled. ${ }^{19}$ Inspire HGNS device requires DISE as a pre-requisite to surgical implantation because CCC is a predictor of nonresponse. The device consists of the single circumferential electrode lead placed around the medial division of XII nerve and the respiratory sensor placed in ipsilateral inter-costal space and a pulse generator.

The ImThera medical device is a modification which excludes the need of inspiratory sensors. This device consists of a pulse generator, and circumferential six electrode leads placed around the main trunk of hypoglossal nerve with cyclical stimulation of the nerve which obviates the need for synchronization with respiration. ${ }^{20}$ As the device does not need a sensory lead, it does not require DISE prior to implantation. Inclusion criteria consisted of BMI between 25 and $40 \mathrm{~kg} / \mathrm{m}^{2}$, AHI more than 20/hour, the modified Mallampatti score between 1 and 3. Currently, this is under phase-III trials.

Apnex system also had circumferential single electrode lead placed around the distal medial division of cranial nerve XII, respiratory sensors placed bilaterally in intercostal spaces and pulse generator in the ipsilateral infraclavicular pocket. The final cup placement on the nerve was based on an intra-operative response of upper airway to stimulation, visualized using fluoroscopy. Inclusion criteria were moderate to severe OSA patients with age 21 to 70 years, BMI $\leq 40 \mathrm{~kg} / \mathrm{m}^{2}$, AHI of 20 to 100 events/hour and all subjects to have a predominance of hypopnea $\geq 80 \%$ of the sum of apnea and hypopnea events. Even though the 6 months follow-up yielded better results, the larger scale phase 2 to 3 trials did not deliver anticipated results. The procedure-related adverse events at 12 months were found to be $71 \%$. Surgically unsuccessful results led to the cessation of device development. $^{21}$

\section{Surgical Procedure}

The implantation procedure is done under general anesthesia. A $5 \mathrm{~cm}$ incision is made one fingerbreadth below the mandibular margin, anteriorly up to midline and posteriorly to the submandibular gland. Dissection is done to identify the hypoglossal nerve. The digastric tendon is identified and retracted inferiorly while submandibular gland is lifted posterosuperiorly. Mylohyoid muscle is identified, and the posterior edge is retracted anteriorly to identify the main trunk of the hypoglossal nerve, which is then traced anteriorly. The medial and lateral branches are identified and confirmed using a nerve integrity monitoring system ((NIM, Medtronic Xome $\left.{ }^{\circledR}\right),{ }^{22}$ and the cuff selectively wraps around the medial branches in Inspire II, while in the ImThera Medical Inc the electrode cuff is rolled under and around the main trunk of the nerve. ${ }^{20}$
The pleural pressure sensing lead is placed through a horizontal incision that is made at the right fourth or fifth intercostal space lateral to the nipple line. Dissection is carried out to the upper border of the underlying rib, and a pocket is tunneled postero-anteriorly between external and internal intercostal muscle layers where the sensing lead faces pleura. ${ }^{23}$

The implantable pulse generator (IPG) connects the nerve stimulation cuff and the pleural sensing electrode. A subcutaneous pectoral pocket is created 2 to $5 \mathrm{~cm}$ inferior to the right clavicle and medial to the deltopectoral groove. Inferiorly the pocket is extended subcutaneously to the pleural sensing electrode. Superiorly, a subplatysmal tunnel is created to the hypoglossal nerve stimulation cuff, and the lead passed downwards and connected to (IPG). After the implantation of the HGNS system, the electrical integrity is confirmed, and the IPG is tested to confirm tongue protrusion.

\section{Stimulation Protocol}

The Inspire II system is activated 4 weeks post-implantation, and the stimulation is given between end expiration through the inspiratory period to minimize neuromuscular fatigue. ${ }^{24}$ Titrations are performed at 1, 2 and 4 months postimplantation.

The ImThera medical system is activated in seated awake patients 3 to 4 weeks after surgery. ${ }^{20}$ Electrodes are stimulated cyclically in a pattern independent of the respiratory cycle and titrations performed at 1 and 12 months postimplantation.

\section{OBJECTIVES}

To evaluate the efficacy of hypoglossal nerve stimulation in the treatment of OSA syndrome as a novel surgical technique.

\section{METHODS}

Studies were included that evaluated the efficacy of hypoglossal nerve stimulation to treat OSA. Six prospective studies were included in this trial.

\begin{tabular}{|c|c|c|c|c|}
\hline Study & Study design & Device used & $\begin{array}{l}\text { Sample } \\
\text { size }\end{array}$ & Findings \\
\hline $\begin{array}{l}\text { Eastwood } \\
\text { et al. }{ }^{25}\end{array}$ & $\begin{array}{l}\text { Prospective } \\
\text { single-arm } \\
\text { interventional } \\
\text { trial }\end{array}$ & $\begin{array}{l}\text { Apnex } \\
\text { (Medical } \\
\text { Inc.) }\end{array}$ & 21 & $\begin{array}{l}\text { Improvement in } \\
\text { AHI from } 43.1 \\
\text { events/hour to } \\
19.5 \text { events/hour } \\
\text { Improvement in } \\
\text { ESS from } 12.1 \pm \\
4.7 \text { to } 8.1 \pm 4.4\end{array}$ \\
\hline $\begin{array}{l}\text { Van de } \\
\text { Heyning } \\
\text { et al. }{ }^{24}\end{array}$ & $\begin{array}{l}\text { Two } \\
\text { consecutive } \\
\text { open } \\
\text { prospective } \\
\text { study }\end{array}$ & $\begin{array}{l}\text { Inspire II } \\
\text { (Medtronics } \\
\text { Inc.) }\end{array}$ & $\begin{array}{l}\text { 21(Part } \\
\text { 1) } \\
8 \text { (Part } \\
\text { 2) }\end{array}$ & $\begin{array}{l}\text { Improvement in } \\
\text { AHI from } 38.9 \pm \\
9.8 \text { to } 10.0 \pm 11.0 \\
\text { Significantly } \\
\text { improved ESS } \\
\text { and FOSQ }\end{array}$ \\
\hline
\end{tabular}


Hypoglossal Nerve Stimulation for Obstructive Sleep Apnea: A Novel Surgical Approach (A Review of Literature)

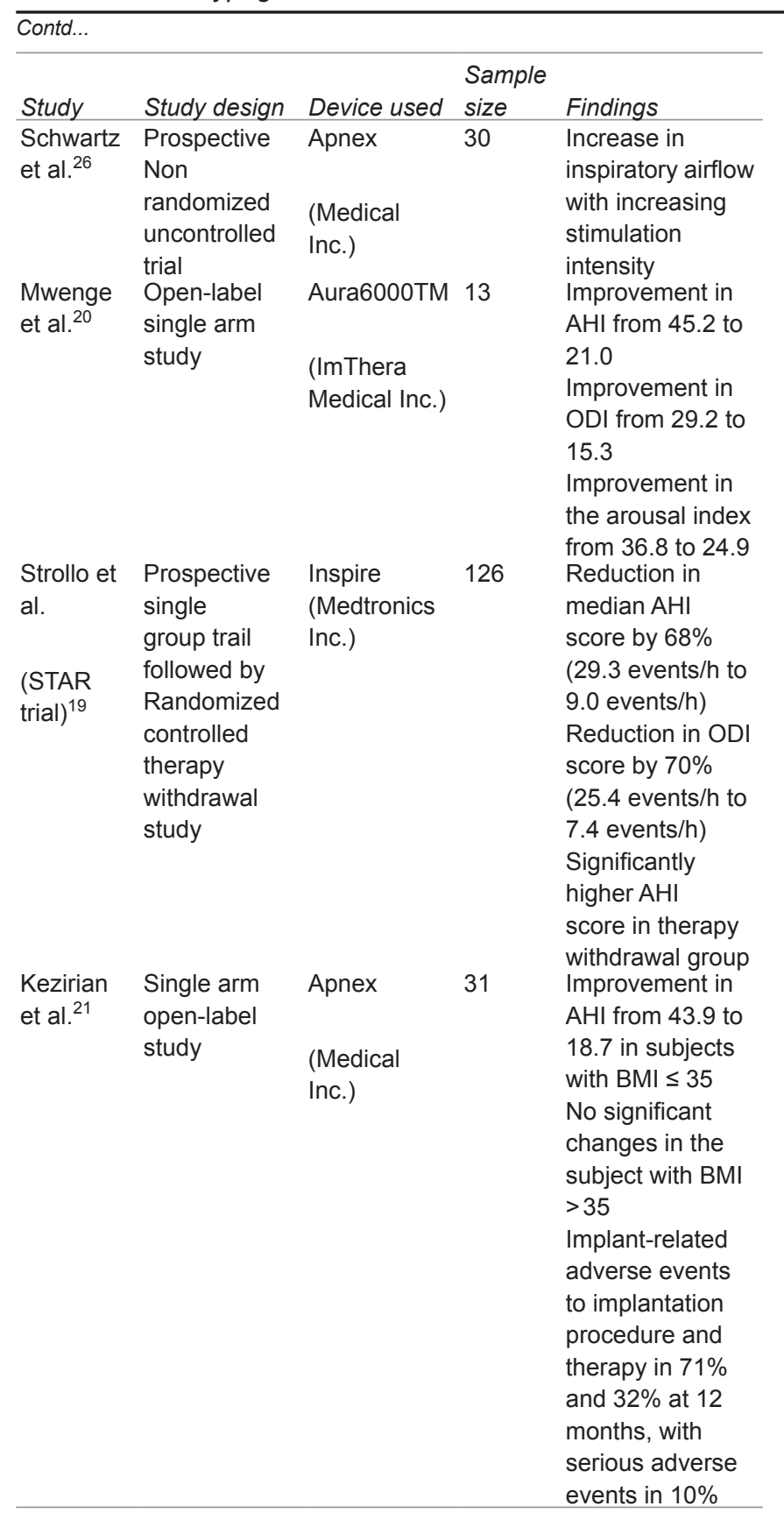

\section{RESULTS}

Six studies with a total of 242 patients were included in this review. All the studies demonstrated reduction in AHI, ODI and ESS. Despite using different hypoglossal nerve stimulators in each subgroup analysis, no significant difference was found in any of the comparisons, suggesting equivalent efficacy regardless of the system in use.

\section{DISCUSSION}

In 2014, Strollo et al. conducted an uncontrolled cohort study on 126 patients (STAR trial) and reported a $68 \%$ decrease in the median AHI score and a 70\% reduction in the ODI score. ${ }^{19}$ Similar results were reported by Van de Heyning et al. in 2012. ${ }^{24}$ Both the studies were conducted using Inspire (Medtronics Inc.) device. In 2012, Schwartz et al. conducted a study on 30 patients using the Apnex (Medical Inc.) device and reported an

increase in inspiratory airflow with increasing stimulation intensity. ${ }^{26}$ Similar results were reported by Eastwood et al. in 2011 using the same device. ${ }^{25}$ However, Kezirian et al. in 2014, reported implant-related adverse events to implantation procedure and therapy in $71 \%$ and $32 \%$ subjects 12 months respectively with four patients requiring explantation of the device. ${ }^{21}$ In 2013, Mwenge et al. in 2013 used the Aura6000TM (ImThera Medical Inc.) on 13 subjects and reported significant improvement in AHI, ODI and arousal index..$^{20}$

Although CPAP, the standard first-line therapy has proved to be highly effective, suboptimal patient compliance has been shown to limit long-term results in many patients. A universally accepted second-line therapy does not exist. The current treatment plan may include oral appliance therapy, weight loss, positional therapy, lowering nasal resistance, and airway reconstructive surgery-often in combination. Even with this variety of second-line options, many patients remain inadequately treated with residual symptoms and persistent health risks and require an effective option. HGNS therapy has been shown to provide safe and effective short-term management in a cohort of moderate-to-severe OSA patients who were unable to achievebenefit with positive pressure therapy. ${ }^{27}$

The HGNS has several unique advantages compared to traditional OSA surgeries:

- It provides multilevel airway improvement with only one procedure

- Upper airway stimulation therapy is a titratable and adjustable therapy, similar to CPAP or even oral appliances.

- Unlike other surgical procedures that provide a one-time result, hypoglossal nerve stimulation parameters can be modified postoperatively through a variety of configurations to optimize effectiveness as well as patient comfort/adherence. ${ }^{28}$

The HGNS therapy has a very favorable risk-benefit profile and is well-positioned as a salvage treatment for patients with moderate-severe OSA, however further studies are needed on long-term adherence and effectiveness as OSA is a chronic condition. Further, more research is required to study the potential role of UAS therapy in patients with a BMI $>32 \mathrm{~kg} / \mathrm{m}^{2}$. Long-term cost-effectiveness of the therapy needs to be determined. Also, there is a need to define the most effective and appropriate stimulation parameters and titration protocols.

\section{Complications and Limitations of Hypoglossal Nerve Stimulation}

Certain adverse effects have been noticed with HGNS. The most common procedure-related event was numbness/pain at the incision sites. Insomnia and other psychological issues were reported both by Kezirian et al. and Strollo et al. Other common adverse events were, the need for implanted pulse generator and sense lead replacement due to unstable sensing performance and dislodgement of the stimulation lead cuff. Kezirian et al. also reported intermittent tongue soreness in few subjects. ${ }^{19,21}$ 
Another limiting factor for HGNS therapy is the incompatibility of the current technology with magnetic resonance imaging (MRI) and the need for three external incisions for implantation. ${ }^{28}$

\section{CONCLUSION}

CPAP remains the gold standard therapy for OSA. HGNS therapy has so far proved to be an effective alternative treatment of obstructive sleep apnoea in CPAP intolerant selected group of patients. However, further scientific studies and research projects are required to establish its long-term results, efficacy as well as cost-effectiveness for this therapy.

\section{REFERENCES}

1. Kuna ST, Sant'Ambrogio G. Pathophysiology of upper airway closure during sleep. Jama. 1991 Sep 11;266(10):1384-1389.

2. Lindberg EV, Carter NE, Gislason T, Janson C. Role of snoring and daytime sleepiness in occupational accidents. American journal of respiratory and critical care medicine. 2001 Dec 1;164(11):2031-2035.

3. Tregear S, Reston J, Schoelles K, Phillips B. Obstructive sleep apnea and risk of motor vehicle crash: systematic review and meta-analysis. Journal of clinical sleep medicine. 2009 Dec 15;5(06):573-581.

4. Sharma SK, Kumpawat S, Banga A, Goel A. Prevalence and risk factors of obstructive sleep apnea syndrome in a population of Delhi, India. Chest. 2006 Jul 1;130(1):149-156.

5. Kushida CA, Littner MR, Hirshkowitz M, Morgenthaler TI, Alessi CA, Bailey D, Boehlecke B, Brown TM, Coleman Jr J, Friedman L, Kapen S. Practice parameters for the use of continuous and bilevel positive airway pressure devices to treat adult patients with sleep-related breathing disorders. Sleep. 2006 Mar 1;29(3):375-380.

6. He J, Kryger MH, Zorick FJ, Conway W, Roth T. Mortality and apnea index in obstructive sleep apnea: experience in 385 male patients. Chest. 1988 Jul 1;94(1):9-14.

7. Ravesloot MJ, De Vries N. Reliable calculation of the efficacy of non-surgical and surgical treatment of obstructive sleep apnea revisited. Sleep. 2011 Jan 1;34(1):105-110.

8. Kushida CA, Morgenthaler TI, Littner MR, Alessi CA, Bailey D, Coleman Jr J, Friedman L, Hirshkowitz M, Kapen S, Kramer M, Lee-Chiong T. Practice parameters for the treatment of snoring and obstructive sleep apnea with oral appliances: an update for 2005. Sleep. 2006 Feb 1;29(2):240-243.

9. Lettieri CJ, Paolino N, Eliasson AH, Shah AA, Holley AB. Comparison of adjustable and fixed oral appliances for the treatment of obstructive sleep apnea. Journal of Clinical Sleep Medicine. 2011 Oct 15;7(05):439-445.

10. Vanderveken OM, Devolder A, Marklund M, Boudewyns AN, Braem MJ, Okkerse W, Verbraecken JA, Franklin KA, De Backer WA, Van de Heyning PH. Comparison of a custommade and a thermoplastic oral appliance for the treatment of mild sleep apnea. American journal of respiratory and critical care medicine. 2008 Jul 15;178(2):197-202.

11. Van de Heyning PH, Badr MS, Baskin JZ, Cramer Bornemann MA, De Backer WA, Dotan Y, Hohenhorst W, Knaack L, Lin HS, Maurer JT, Netzer A. Implanted upper airway stimulation device for obstructive sleep apnea. The Laryngoscope. 2012 Jul;122(7):1626-1633.

12. Oliven A. Treating obstructive sleep apnea with hypoglossal nerve stimulation. Current opinion in pulmonary medicine. 2011 Nov 1;17(6):419-424.
13. Kezirian EJ, Boudewyns A, Eisele DW, Schwartz AR, Smith PL, Van de Heyning PH, De Backer WA. Electrical stimulation of the hypoglossal nerve in the treatment of obstructive sleep apnea. Sleep medicine reviews. 2010 Oct 1;14(5):299-305.

14. Remmers JE, DeGroot WJ, Sauerland EK, Anch AM. Pathogenesis of upper airway occlusion during sleep. Journal of Applied Physiology. 1978 Jun 1;44(6):931-938.

15. Steier J, Seymour J, Rafferty GF, Jolley CJ, Solomon E, Luo Y, Man WD, Polkey MI, Moxham J. Continuous transcutaneous submental electrical stimulation in obstructive sleep apnea: a feasibility study. Chest. 2011 Oct 1;140(4):998-1007.

16. Smith PL, Eisele DW, Podszus T, Penzel T, Grote L, Peter JH, Schwartz AR. Electrical stimulation of upper airway musculature. Sleep. 1996 Dec 1;19(suppl_10):S284-S287.

17. Randerath WJ, Galetke W, Domanski U, Weitkunat R, Ruhle $\mathrm{KH}$. Tongue-muscle training by intraoral electrical neurostimulation in patients with obstructive sleep apnea. Sleep. 2004 Mar 15;27(2):254-259.

18. Schwartz AR, Bennett ML, Smith PL, De Backer W, Hedner J, Boudewyns A, et al. Therapeutic electrical stimulation of the hypoglossal nerve in obstructive sleep apnea. Archives of Otolaryngology-Head \& Neck Surgery. 2001 Oct 1;127(10):12161223.

19. Strollo Jr PJ, Soose RJ, Maurer JT, De Vries N, Cornelius J, Froymovich $\mathrm{O}$, et al. Upper-airway stimulation for obstructive sleep apnea. New England Journal of Medicine. 2014 Jan 9;370(2):139-149.

20. Mwenge GB, Rombaux P, Dury M, Lengelé B, Rodenstein D. Targeted hypoglossal neurostimulation for obstructive sleep apnoea: a 1-year pilot study. European Respiratory Journal. 2013 Feb 1;41(2):360-367.

21. Kezirian EJ, Goding Jr GS, Malhotra A, O'donoghue FJ, Zammit G, Wheatley JR, et al. Hypoglossal nerve stimulation improves obstructive sleep apnea: 12 month outcomes. Journal of sleep research. $2014 \mathrm{Feb}$;23(1):77-83.

22. Heiser C, Hofauer B, Lozier L, Woodson BT, Stark T. Nerve monitoring-guided selective hypoglossal nerve stimulation in obstructive sleep apnea patients. The Laryngoscope. 2016 Dec;126(12):2852-2858.

23. ok Hong S, Chen YF, Jung J, Kwon YD, Liu SY. Hypoglossal nerve stimulation for treatment of obstructive sleep apnea (OSA): a primer for oral and maxillofacial surgeons. Maxillofacial plastic and reconstructive surgery. 2017 Dec 1;39(1):27.

24. Van de Heyning PH, Badr MS, Baskin JZ, Cramer Bornemann MA, De Backer WA, Dotan Y, et al. Implanted upper airway stimulation device for obstructive sleep apnea. The Laryngoscope. 2012 Jul;122(7):1626-1633.

25. Eastwood PR, Barnes M, Walsh JH, Maddison KJ, Hee G, Schwartz AR, et al. Treating obstructive sleep apnea with hypoglossal nerve stimulation. Sleep. 2011 Nov 1;34(11):14791486.

26. Schwartz AR, Barnes M, Hillman D, Malhotra A, Kezirian E, Smith PL, et al. Acute upper airway responses to hypoglossal nerve stimulation during sleep in obstructive sleep apnea. American journal of respiratory and critical care medicine. 2012 Feb 15;185(4):420-426.

27. Soose RJ, Padhya TA, Gillespie MB, Froymovich O, Lin HS, Woodson BT, STAR Trial Investigators. OSA treatment history in an upper airway stimulation trial cohort. World journal of otorhinolaryngology-head and neck surgery. 2017 Jun 1;3(2):79-84.

28. Dedhia RC, Strollo Jr PJ, Soose RJ. Upper airway stimulation for obstructive sleep apnea: past, present, and future. Sleep. 2015 Jun 1;38(6):899-906. 